\title{
INSTRUMENTALIDADE DO DIREITO AO DESENVOLVIMENTO PARA A CONCRETIZAÇÃO DO DESENVOLVIMENTO HUMANO: PILARES DA IGUALDADE E DA LIBERDADE
}

\author{
Adrianna de Alencar Setubal Santos ${ }^{1}$ \\ Maria Aurea Baroni Cecato ${ }^{2}$
}

\section{RESUMO}

O debate sobre o desenvolvimento cresceu nas discussões políticas e científicas que reagiram às ofensas à dignidade humana a partir da Segunda Guerra. Desde então, o termo passa por ressignificação de carga qualitativa valiosa, responsável por colocar o crescimento econômico como instrumento e não mais como fito da ação estatal. A ordem internacional reconhece, hoje, um direito ao desenvolvimento humanístico, que permite a consolidação de novo ideal de desenvolvimento. Nesse contexto, a proposta do artigo é a consideração da instrumentalidade do direito ao desenvolvimento para o desenvolvimento humano $\mathrm{e}$ fundamentação nos pilares da igualdade e da liberdade.

Palavras-chave: Desenvolvimento. Igualdade. Liberdade. Instrumentalidade. Direito ao desenvolvimento.

\section{INSTRUMENTALITY OF THE RIGHT TO DEVELOPMENT FOR THE CONCRETION OF HUMAN DEVELOPMENT: PILLARS OF EQUALITY AND FREEDOM}

\begin{abstract}
The debate on development has grown in the political and scientific discussions that have reacted to offenses against human dignity since World War II. Since then, the term has undergone a re-signification of valuable qualitative content, responsible for placing economic growth as an instrument, rather than a goal of state action. The international order recognizes, nowadays, a right to humanistic development, which has allowed the consolidation of a new ideal of development. In this context, this article proposes to consider the instrumentality of the right to development for the human development, with substantiation in the pillars of equality and liberty.
\end{abstract}

Keywords: Development. Equality. Liberty. Instrumentality. Right to development.

\footnotetext{
${ }^{1}$ Mestre em Direito Comercial pela PUC/SP. Doutoranda em Direitos Humanos e Desenvolvimento pela UFPB. Professora do Curso de Direito da Universidade Federal do Piaui. E-mail adria_santos@yahoo.com.br ; adriannasetubal@ufpi.edu.br

${ }^{2}$ Doutora em Direito do Trabalho pela Université de Paris II: Professora Permanente do PPGD/UNIPÊ e colaboradora do PPGCJ/UFPB. Líder do Grupo de Pesquisa Trabalho e Desenvolvimento: influxos e dissensões/CNPQ. E-mail mariaaurea.cecato@gmail.com
} 


\section{INTRODUÇÃO}

Este artigo trata da instrumentalidade do direito ao desenvolvimento para a difícil materialização do desenvolvimento humano, considerando, ao mesmo tempo, a relevância dos esteios da liberdade e da igualdade nesse mesmo propósito.

Para contextualizar essa proposta, releva considerar que, em tempos de crise humanitária, discutir a implementação do desenvolvimento é, minimamente, tarefa delicada, chegando a ser, por vezes, constrangedora. Submetido a um processo de reformulação desde as últimas décadas do século passado, como reação às ofensas à dignidade humana nascidas no seio da Segunda Guerra Mundial, ainda peleja por efetivação significativa no avançar do primeiro quartel do século XXI.

De resto, o maior relevo deste texto sedia-se justamente no fato de que se tem avançado pouco na concretização do desenvolvimento humano. Parece que, ao invés de prosperar, recua-se em diversos aspectos a ele atinentes, ao contrário do que se poderia ainda esperar nas últimas décadas do Século passado.

Releva considerar, nesse quadro, que, direcionado para horizonte menos quantitativo, o desenvolvimento não pode, entretanto, desprezar a importância do crescimento econômico e sua representação numérica, diante de seu destaque no âmbito da satisfação das necessidades humanas. Por outra, é dizer que a nova compreensão do termo desenvolvimento decorre do reconhecimento da insuficiência do elemento econômico como medida de bem-estar e de satisfação de direitos humanos, sem, entretanto, desprezá-lo enquanto parte do complexo processo de desenvolvimento.

Nesse ambiente de formatação de um novo paradigma para o desenvolvimento, o direito tem assumido papel importante na medida em que, hodiernamente, recebe o desenvolvimento como direito de viés mais humano, o chamado direito ao desenvolvimento, em contraposição ao direito do desenvolvimento, de verve mais econômica. É aquele, com sua perspectiva mais qualitativa, o que servirá para debate nesse trabalho, considerando-se que ele cuida de uma via de concretização do desenvolvimento humano.

Assim sendo, este artigo visa compreender o direito ao desenvolvimento enquanto suporte do desenvolvimento humano, assinalando, nesse mesmo quadro, a eminência dos esteios da liberdade e da igualdade. Usa o método dedutivo e utiliza textos que resultam de estudos sobre a temática, além de documentos normativos internacionais e nacionais pertinentes, notadamente os que, direta ou indiretamente se referem ao desenvolvimento humano. Como problema, questiona qual a importância da existência de um direito ao 
desenvolvimento e da presença dos elementos liberdade e igualdade no processo do desenvolvimento humano.

A abordagem do que se propõe contempla três seções: a primeira versa sobre as ressignificações e trajetória do direito ao desenvolvimento; a segunda trata da formação do direito ao desenvolvimento e a terceira e última debruça-se sobre os elementos igualdade e liberdade no contexto do desenvolvimento subdividindo-se em duas subseções que discorrem, uma especificamente sobre a igualdade e a outra sobre a liberdade, esta valorizando a percepção de Amartya Sen.

\section{DESENVOLVIMENTO E DIREITO AO DESENVOLVIMENTO: (RE)SIGNIFICAÇÕES E TRAJETÓRIA DE CONSTRUÇÃO}

Por muito tempo, tratar de desenvolvimento significou representar números e projeções de crescimento econômico revelados em planos de ação governamental e como sinônimo de progresso.

Nesse sentido, Coutinho (2013, p. 29) informa que, entre os anos de 1950 e 1960, o termo conquistou o seu espaço diante do ambiente de industrialização fortemente marcado por investimentos em capital físico e infraestrutura, base para aquele processo e medida do desenvolvimento à época.

Até então, discutir o desenvolvimento era abordar questões relativas ao crescimento econômico enquanto "medida da riqueza material de um país" (CAMPINHO, 2010, p. 158), cuidando de ambiente que implicava em investigações acerca do aumento da capacidade produtiva.

Na década seguinte, iniciou-se um movimento mundial em razão do qual se reconheceu a insuficiência do parâmetro quantitativo, próprio do crescimento econômico, como medida do desenvolvimento. Os aspectos humanos passaram a constituir variáveis do processo de desenvolvimento e de um novo direito, o "direito ao desenvolvimento" construído na fala de Keba M’Baye, durante um curso de Direitos Humanos do Instituto de Direitos do Homem em Estrasburgo, no ano de 1972. Inaugurou-se, por esse pronunciamento, nova referência de desenvolvimento, crescentemente fortificada e definitivamente recebida pela comunidade internacional por ocasião do Colóquio da Academia de Direito Internacional de Haia no ano de 1979 (DELGADO, 2001, p. 85).

Estava aberto o caminho para a ressignificação do desenvolvimento, reconstruído a partir de debates mundiais e publicações responsáveis por promover a construção das bases 
conceituais de uma nova medida de crescimento e de um novo direito, cada vez mais distanciado do cumprimento de metas quantitativas e mais avizinhado de um ideal de crescimento com equidade, voltado para a inclusão de "metas como alívio direto da pobreza, emancipação das mulheres, proteção das minorias, liberdade política, acesso à justiça e segurança jurídica", em evidente reconfiguração dos parâmetros desenvolvimentistas (TRUBEK, 2009, p. 221).

O desenvolvimento, então, passou a ser visto como um

[...] processo ao mesmo tempo econômico, social, cultural e político que visa ao constante incremento do bem-estar de toda a população e de todos os indivíduos com base em sua participação ativa, livre e significativa no desenvolvimento e na distribuição justa dos benefícios dele resultantes (CAMPINHO, 2010, p. 158).

Ao tempo da Carta Africana dos Direitos Humanos e dos Povos, no ano de 1981, o debate sobre desenvolvimento e sobre direito ao desenvolvimento já não encontrava limites, passando a ser reconhecido como um direito dos povos e dos indivíduos a ser exercido em face dos Estados.

Na década de 1980, não obstante não se pudesse - como de fato não se pode - falar em desenvolvimento de forma desvinculada de crescimento econômico, o "novo desenvolvimento" continuou sua propagação apesar do retardo na sua efetivação em esfera mundial provocado pela crise do petróleo e pela recessão.

Mas a construção do "novo desenvolvimento" seguiu se afastando da concepção de crescimento econômico ou desenvolvimento-meta, voltando-se na direção do desenvolvimento-direito, ou, como propõe FEITOSA (2013, p. 174) "direito humano ao desenvolvimento", marcado pela atuação cooperativa nas ações de desenvolvimento em esfera interna e internacional.

A Declaração sobre o Direito ao Desenvolvimento (ONU, 1986) ${ }^{3}$ foi referência na formatação do direito ao desenvolvimento, tendo sido uma baliza no seu tratamento como direito humano universal e inalienável, enunciado entre os direitos fundamentais, efetivado com a consolidação de valores democráticos (SOARES, 2010, 468).

Para Piovesan a importância da Declaração em matéria de sistematização do direito ao desenvolvimento se deu em razão de

[...] lançar o human-rights-based approach ao direito ao desenvolvimento. Sob a perspectiva dos direitos humanos, o direito ao desenvolvimento compreende como relevantes princípios: a) o princípio da inclusão, igualdade e

\footnotetext{
${ }^{3}$ Resolução 41/1986 da Assembleia Geral das Nações Unidas da ONU.
} 
não discriminação (especial atenção deve ser dada à igualdade de gênero e às necessidades dos grupos vulneráveis); b) o princípio da accountability e da transparência; c) o princípio da participação e do empoderamento (empowerment), mediante livre, significativa e ativa participação; e d) o princípio da cooperação internacional (PIOVESAN, 2010, p. 105).

$\mathrm{O}$ direito ao desenvolvimento passou, assim, a ser reconhecido como um direito humano, interdependente e indivisível em relação aos demais direitos e ao mesmo tempo um direito inalienável do ser humano e de todos os povos. Um direito que tem base na justiça social, na igualdade, na liberdade e na cooperação entre agentes e povos.

Desse modo, o desenvolvimento-direito surgido como uma construção doutrinária destinada a resgatar a valorização do ser humano, passou a servir como medida da dignidade e de qualidade de vida dos povos e dos indivíduos, "incorporando um conjunto de métodos e preocupações novos, tal como a definição e mensuração da pobreza, da miséria ou extrema pobreza" (COUTINHO, 2013, p. 31).

A visão reducionista de desenvolvimento como crescimento econômico, em processo de enfraquecimento desde a década de 1970, seguiu perdendo espaço para a sua ressignificação de base humanista introduzida nas diversas ordens jurídicas internas pela adesão de países como o Brasil, a documentos internacionais voltados para a promoção do direito ao desenvolvimento.

Não obstante tal fato, a inserção da recente visão de desenvolvimento e do direito ao desenvolvimento não inviabilizou - nem deveria - a permanência dos modelos de crescimento econômico que foram mantidos por sua relevância na distribuição de benefícios à população e pela perspectiva de contribuírem com o fim da pobreza, na medida em que se apresentem como sustentáveis. Restou, assim, compreendida a interdependência existente entre a edificação do modelo humano de desenvolvimento e de crescimento econômico em razão do qual é conferida a proteção e o respeito à dignidade do ser humano e a redução das desigualdades (SACHS, 2005, p. 57).

Persistiu evidenciada, portanto, a vigorosa importância das questões econômicas mesmo diante dessa renovada compreensão do desenvolvimento, especialmente considerando que no seu centro há o trabalho enquanto matriz de análise e medida do crescimento econômico (CALLEGARI, 2010, p. 491). E existindo relação de dependência entre trabalho e crescimento, inevitavelmente sua repercussão se fará sentir no exercício do direito ao desenvolvimento, com sua marca de humanidade. 
Na fala autorizada de Nusdeo (2016, p. 304) surge também o reforço à ideia de que o desenvolvimento é um processo que não se resume à promoção e elevação da renda per capita em determinado período. É, para além disso, representação de indicadores, situações e modificações de ordem qualitativa e quantitativa, promotores de uma mudança estrutural da economia e, assim, da sociedade. Desse modo, destaca-se que mesmo sendo opção a representação por grandezas quantitativas, há que se ter presente a existência de referências qualitativas, daquelas indissociáveis.

Muitas são as contribuições no sentido da construção de referências científicas para o novo desenvolvimento e seu direito instrumental. Em Feitosa (2012, p. 41-43), essa nova compreensão do fenômeno do desenvolvimento o admite em ambiente de cooperação entre o Estado e os outros agentes econômicos, viabilizando a coexistência das dimensões econômica, com a estabilidade e o crescimento macroeconômico, social e humano, com o estabelecimento de garantias de bem-estar geral, de inclusão social e sustentabilidade ambiental, com o desenvolvimento do meio ambiente.

Para Fachin (2010, p. 197), tratar do direito ao desenvolvimento implica reconhecer seu caráter "transindividual", voltado para os agentes estatais e "individual", dirigido para uma razão mínima de liberdade substancial orientadora de uma existência digna e permissiva de sua autodeterminação como ser humano. Em complementação, em Soares (2010, p. 469), agregam-se ao respeito à dignidade humana o "elo intra e intergeracional". Nessa perspectiva, o desenvolvimento encontra sua via de sustentabilidade enquanto processo e prática continuada e longeva.

Em suma, serve a construção de Callegari para quem o direito ao desenvolvimento é “a colocação jurídica do problema do desenvolvimento econômico" (2010, p. 493). Todavia, há que se não olvidar que a construção desse direito está radicada na compreensão da necessária inclusão de todos em todos os processos que levam ao desenvolvimento, sendo, em última análise, a inclusão de todos em todas as dimensões do desenvolvimento.

Mas, como adiante se discorrerá, frente a esse novo desenvolvimento e ao direito ao desenvolvimento, no que toca ao presente trabalho, propõe-se a incursão, ainda que breve, sobre noções que surgem como base para a sua configuração, assim, a igualdade e a liberdade entendidas nessa sede como determinantes para a efetivação do desenvolvimento.

\section{FORMAÇÃO DO DIREITO AO DESENVOLVIMENTO}


Como dito anteriormente, as últimas décadas do século passado presenciaram a criação de nova referência para o desenvolvimento e para um novo direito, o direito ao desenvolvimento.

Desse modo, considerando a proposta de discussão acerca da instrumentalidade e materialização do direito ao desenvolvimento, parece oportuno trazer para o debate os elementos de sua formação. Com efeito, estes últimos se revelam necessários à consolidação do direito criado e conseqüente utilização por seus destinatários.

Partindo do desenvolvimento, entender a natureza jurídica do direito ao desenvolvimento é discutir as possibilidades de sua implementação, seus instrumentos de concreção e sua "sindicabilidade por meio da adjudicação pelos seus titulares" (CAMPINHO, 2010, p. 159).

Proposto diante da formação da ideia de desenvolvimento humano no pós guerra, exsurge como razão para a gênese do direito ao desenvolvimento a proteção a valores que compõem a dignidade da pessoa humana. Enquanto direito humano ${ }^{4}$, fundamental, apresentase como via para a concretização de acessos que constituem a base do desenvolvimento humano e que, titularizados pelos homens, são, em regra, oponíveis ao Estado, responsável pela condução de políticas públicas de implantação das variáveis do desenvolvimento, quais seja, o acesso à saúde, à informação, à educação, à segurança, ao emprego, à cultura e ao lazer, dentre outros.

Ainda que não se pretenda discutir o enquadramento do direito ao desenvolvimento enquanto direito humano e universal, parece oportuno o destaque no sentido de contemporaneamente vê-lo caracterizado como "processo de universalização e internacionalização destes direitos, compreendidos sob o prisma de sua indivisibilidade" (PIOVESAN, 2010, p. 100).

No que tange, portanto, aos pólos subjetivos do direito ao desenvolvimento, a visão particular é a que identifica no titular do direito também um colaborador, seu agente, voltado e integrado ao processo de construção do crescimento humano e não um mero fator de produção do desenvolvimento.

\footnotetext{
${ }^{4}$ A propósito do seu reconhecimento como direito fundamental, outros debates são travados com o objetivo de categorizar o direito ao desenvolvimento como direito humano. Para maiores aprofundamentos vide a obra de Amartya Sen, em Desenvolvimento como Liberdade, Bernardo Brasil Campinho, Carla Abrantkosky Rister e Melina Girardi Fachin, nos textos indicados nas referências.
} 
A configuração de direito inalienável reforça sua aproximação com os elementos da dignidade humana, mantendo a devida distância das referências instrumentais que envolvem a atuação do homem no processo de desenvolvimento (Delgado, 2001, p. 100).

Mas a caracterização clássica do direito subjetivo ao desenvolvimento, não se revelou suficiente para qualificar o direito ao desenvolvimento. Desse modo, não obstante se possa reconhecer sua dimensão coletiva decorrente da associação de vários interesses, a implementação do direito ao desenvolvimento demanda a formulação de políticas sociais, econômicas e culturais, de maneira que acaba por servir e beneficiar não somente aquele que buscou a efetivação do direito, mas, ao contrário, estende seus efeitos para um universo irrestrito de beneficiários (CAMPINHO, 2010, p. 159).

Diante do exercício assegurado aos cidadãos, nasce o dever correlato que no caso do direito ao desenvolvimento, se impõe, em última análise, ao Estado. Em derradeira instância é ele, de fato, que deverá garantir o bem-estar, para além de dever se consolidar como parceiro cooperativo desse processo.

Nesse contexto, cara é a visão de Sen (2010, p. 295-297) ao reforçar, no campo da coerência, a necessidade de se estabelecer o "contra quem" relativo ao exercício de um direito. Sendo o direito pretensão à qual se correlaciona um dever, construir o direito ao desenvolvimento implica também em definir a forma do seu exercício, no sentido de permitir, ao sujeito, o reconhecimento a priori do responsável pelo cumprimento de dever.

Nesse contexto de cooperação, entende Rister (2007, p. 130) que as capacidades humanas seriam sustentadas pelo Estado e não providas exclusivamente por ele, de maneira que todos os agentes teriam papéis importantes no fortalecimento dessas mesmas capacidades.

Para melhor compreender esse ambiente de atuação do Estado, servem as lições de Grau (2010, p. 92) para quem o Estado tem, como via de ação, a intervenção e a atuação. Enquanto na atuação estatal, a ação do Estado se dá na esfera da atividade em sentido amplo e na área de sua titularidade própria, quer na esfera pública, quer na privada, de outro lado, na intervenção, o agir estatal é restrito à ação na esfera de titularidade do setor privado.

Avançando na formulação das categorias de intervenção, Grau (2010, p. 92) identifica tipos de intervenção. Assim, a intervenção por absorção, presente quando o Estado titularizar setores da atividade econômica em sentido estrito; intervenção por participação, diante do controle pelo Estado de parte dos meios de produção e/ou troca de determinado setor da atividade econômica em sentido estrito, sendo agente em competição com o setor privado; intervenção por direção, que tem o Estado exercendo pressão sobre a economia, no 
sentido de definir mecanismos e normas de comportamento para os exercentes de atividade econômica em sentido estrito e, por fim, a intervenção por indução, que tem o Estado como o agente que maneja os instrumentos de intervenção em atenção às leis disciplinadoras do mercado.

A importância desse quadro representativo da ação do Estado é o potencial de alavancagem para o desenvolvimento que o mesmo poderia assegurar diante da identificação dos comportamentos e ações possíveis do fazer estatal. Não obstante fosse essa a expectativa, Rister (2010, p. 50), ao contrário, reconheceu nos esquemas de intervenção, uma experiência de fracasso, entendendo ter sido mesmo uma das razões para o surgimento do direito humano ao desenvolvimento.

Assim, se por um lado ao Estado é imposto o dever objetivo de assegurar ao particular o exercício do direito subjetivo ao desenvolvimento, é, por outro, o promotor do desenvolvimento, de modo a deixar ao mercado a posição de coadjuvante nesse processo (FURTADO, 2002, p. 8).

A esse respeito

[...] se se admite que o processo de desenvolvimento não se dá naturalmente pelo livre jogo das forças de mercado, mas deve ser planejado e dirigido pelos Poderes Públicos com a participação de todo o povo, pode parecer óbvio que o direito ao desenvolvimento deve ser exercido, primariamente, contra o Estado, entendido como o conjunto dos órgãos de governo. (RISTER, 2010, p. 57)

Ao Estado cabe, dessa feita, revisitar suas estruturas tradicionais de poder para que possa, em medida justa, intervir na esfera empresarial, promovendo a proteção aos interesses não empresarias. Essa forma de ação seria própria do direito ao desenvolvimento.

Sendo direito dos povos, a titularidade do direito ao desenvolvimento é coletiva ou difusa e aos Estados ficaria reservado o papel de sujeitos passivos e não de credores do direito ao desenvolvimento. Todavia, esse papel de sujeito passivo do Estado não é absoluto, eis que se encontram referências que, baseadas na autodeterminação dos povos, inerente ao direito ao desenvolvimento, admitem a titularidade coletiva pelos Estados-nação (CAMPINHO, 2010, p. 162). Dessa autodeterminação nasceria o próprio fazer estatal, representado no projeto nacional de desenvolvimento a ser construído.

A parte o debate relativo à titularidade subjetiva do Estado no direito ao desenvolvimento, nascida da Declaração da ONU de 1993, há que se reconhecer que o instrumental do novo direito encontra seu correlato no dever do Estado de sustentar o 
desenvolvimento, em regência cooperada com os demais sujeitos envolvidos, com vistas à efetiva implantação do processo de desenvolvimento.

Mas, para além das questões amplitude e destinatário desse direito, o destaque deve ser feito às trajetórias a serem adotadas para a implementação do direito ao desenvolvimento que, como sabido, exigem uma postura ativa do Estado, sendo regente e agente desse processo, sem descuidar da necessária atuação dos cidadãos, também responsáveis por um fazer individual colaborativo e promotor do desenvolvimento humano (SANTOS, 2017, p. 14).

No percurso que envolve o redimensionamento do desenvolvimento, significativa é a diferenciação entre o desenvolvimento-direito e o direito aos seus frutos. Soares observa que, no " [...] direito ao desenvolvimento a pessoa humana é o sujeito central e prioritário, enquanto no direito aos frutos os interesses relativos ao próprio processo de desenvolvimento são mensurados e compatibilizados com a pessoa humana." (2010, p. 473).

É ainda Soares que, complementando sua reflexão, refere que, conquanto "[...] os frutos do desenvolvimento imprimam resultados imediatos na economia local, a repercussão econômica das atividades e empreendimentos realizados no bojo do processo de desenvolvimento nem sempre é apropriada pela comunidade.” E é por essa razão que “[...] a elaboração e a implementação de políticas públicas devem se pautar na concepção de que o desenvolvimento é um processo que almeja atingir a vida digna." Fica claro, portanto, que "a projeção dos resultados das atuações que objetivam o desenvolvimento deve ser também analisada e discutida na perspectiva da comunidade e não somente numa quantificação do ganho econômico para setores específicos. (2010, p. 473).

Diante de todos os debates apresentados sobre a natureza jurídica e titularidade do direito ao desenvolvimento, acertada parece ser a conclusão de Campinho que o afasta do modelo clássico de direito subjetivo, cujo titular é um sujeito de direito particular ao qual é atribuída uma prestação específica. Diz o autor que o direito ao desenvolvimento é

[...] a união da política e do princípio enquanto norma jurídica, desempenhando as funções: a) de revogar normas e inibir políticas que lhe sejam contrárias; b) de padrão de justiça que deve ser observado na formulação de leis e políticas públicas, conformando-os e legitimando-os; c) de instrumento para reforçar e ampliar a exigibilidade de direitos humanos (civis, políticos, sociais econômicos e culturais), articulando-os com o núcleo essencial do desenvolvimento enquanto direito humano e possibilitando o deferimento de prestações positivas singulares, individuais ou coletivas, ou mesmo de benefícios e fruições de bens e direitos (financiamento, cooperação técnica, serviços ou prestações materiais, etc.) para grupos, entidades, regiões e países. (2010, p. 161). 
Para Green, "a chave do sucesso ou do fracasso do desenvolvimento reside na interação entre Estados e cidadãos" $(2009$, p. 23$)$. Parece, portanto, fortalecida a noção de que mais importante que identificar o titular do direito subjetivo, é reconhecer os agentes do processo de desenvolvimento, melhor identificados como parceiros ou colaboradores desse processo.

Em sede de conclusão da presente seção, vale o registro de Callegari (2010, p. 494) no sentido de que o direito ao desenvolvimento não comporta exclusão dos seus titulares individuais de maneira que a todos devem ser garantidas condições para que desfrutem dos benefícios gerados pelo desenvolvimento humano. ${ }^{5}$

\section{IGUALDADE E LIBERDADE NO CONTEXTO DO DESENVOLVIMENTO}

A compreensão do novo desenvolvimento tem reunido vozes no sentido de promover a consolidação das bases científicas do direito ao desenvolvimento enquanto instrumento para a consecução de mudança estrutural e transformadora das mais diversas realidades sociais.

Em Perroux (1981, p. 31), o assim chamado "novo desenvolvimento", apresenta-se em viés global, integrado e endógeno. Desse modo, aplica-se tanto em dimensões territoriais específicas, determinadas, como em regiões de nações, em nações específicas ou no globo, sempre considerando as variáveis internas, em contraposição ao movimento que considera o desenvolvimento uma grandeza passível de importação, além da integração que pode ser identificada no diálogo inter-regional ou na interação entre setores e classes sociais.

De ampla reflexão pode-se inferir que, estando consolidadas as bases subjetivas sobre as quais se encontra erigida a estrutura do desenvolvimento, o debate sobre o tema continua permitindo, e mesmo demandando, pesquisas e debates como os relativos à própria concreção desse novo desenvolvimento e do seu direito instrumental.

A atualidade do debate se põe em termos bastante simples e tem origem na pluralidade de conceitos que compõem esse novo fazer desenvolvimentista, a envolver a vivência da paz, a presença da economia, a preservação do meio ambiente, o acesso à justiça e o exercício da democracia, para os quais se entende fundamental a presença da igualdade e da liberdade (RISTER, 2010, p. 67).

\footnotetext{
5 Nesse mesmo norte, destaca Cecato (2008, p. 188), que o direito ao desenvolvimento "[...] não admite exclusões; nem de direitos, nem de sujeitos", posto que "constitui o mais íntegro dos direitos fundamentais", encerrando todos os demais e pressupondo, para sua concretização "[...] dois requisitos essenciais: 1) que os direitos humanos e fundamentais sejam todos exercidos; 2) que sejam exercidos por todos".
} 
Por oportuno, importa destacar que, longe de esgotar ou mesmo de aprofundar debates sobre essas variáveis do desenvolvimento, a discussão que se seguirá tem somente o objetivo de despertar novas reflexões acerca dos caminhos para a implementação do desenvolvimento e para o exercício do direito instrumental a este relacionado.

\subsection{Acerca da igualdade}

Estando entre as grandes contribuições da filosofia política, os fundamentos da igualdade podem ser encontrados mesmo entre os céticos da centralidade da "justiça distributiva" e nos utilitaristas, os quais admitem a igualdade de tratamento entre as pessoas conferindo igual importância aos resultados positivos e negativos alcançados por todos, mesmo que em essência negassem a igualdade das utilidades a serem usufruídas pelas diferentes pessoas (SEN, 2011, p. 326).

Questão que vale observação por apresentar relevância no novo significado de desenvolvimento é o tratamento da igualdade como categoria associada à solidariedade. Essa associação se evidencia no fato de que o mencionado novo significado de desenvolvimento se destaca por pressupor a inclusão social, ao contrário do conceito que o antecede, onde o crescimento econômico, por si só - ou seja, mesmo que concentrado nas mãos de minorias representa desenvolvimento. A solidariedade, aliás, costuma ser considerada base da igualdade, fato que se mostra bastante evidente na construção dos direitos sociais e que aparece nitidamente em estudos acerca desta última. Nesse norte, Peres Luño (2005, p. 101), abordando as dimensões da igualdade formal e material, observa que "Igualdad y solidariedad vienem a ser como los Géminis de esse peculiar Zodíaco que conforma el universo de los valores jurídicos". Ainda segundo Luño, as duas categorias mantêm, entre si, relação estreita que chega a "[...] hacer borroso su respectivo sentido y alcance, hasta el punto de que es imposible profundizar en ele significado de cualquiera de ellas sin traspasar los limites de la otra."

Assim, oportuno refletir sobre a intervenção da igualdade na esfera do desenvolvimento. Uma avaliação próxima da realidade não se faz sem considerar indicadores de desigualdade na expectativa de que, mesmo diante da aparente contradição, seja possível, refletindo sobre a superação daquela, alcançar a igualdade vista como categoria indispensável à compreensão de desenvolvimento. De resto, vale considerar, ainda, que a igualdade é um ideal a partir do qual, a desigualdade - seu contraponto - deve ser objeto de redução em um processo permanente. Dito de outra maneira, considerando que a concreção da igualdade não se verifica mediante um exercício meramente conceitual, faz-se necessário reconhecer e 
analisar a segmentação empírica da vivência igualitária e a formação de subconjuntos criados a partir do estabelecimento de parâmetros de igualdade.

A busca da igualdade, partindo dessa premissa, tem como marca a formação de arranjos por semelhanças que não sendo conglobantes, exteriorizam desigualdades e revelam a ausência do caráter unificador do igualitarismo (SEN, 2001, p. 47). Desta feita, é possível afirmar que na construção de espaços de igualdades nasce, ou ao menos poderá nascer, a própria desigualdade.

Como referido, para o estudo da igualdade que aqui nos importa, recorrer-se-á ao tratamento da desigualdade e, com o escopo de garantir a coerência do debate, a discussão será construída em termos de distribuição de renda. Desta feita, ainda que se considere reducionista a investigação do desenvolvimento sob esse viés, mas entendendo a variável renda como valioso mecanismo de solução ou redução da pobreza, será a partir dessa que se terá erigida a argumentação em torno da implementação do processo de desenvolvimento (SEN, 2010, 120-129).

Nesse sentido, estudos científicos foram realizados com o objetivo de investigar a correlação entre crescimento e renda. Apresentados por Coutinho (2013, p. 47-48), apontam para a existência de um crescimento mais sustentado nas sociedades mais iguais do que o experienciado em sociedades desiguais, correlação que se reproduziu também em relação ao ritmo de crescimento.

Dessa forma, Dagdeviren et al consideram que

Perhaps, the most important is the growing consensus in the literature that countries with an 'initial condition' of relatively egalitarian distribution of assets and income tend to grow faster than countries with high initial inequality. For our purposes this is an extremely important conclusion because it means that reducing inequality 'cuts both ways'. On the one hand, a growth path characterised by greater equality at the margin directly benefits the poor in the short run. On the other, the resulting decrease in equality creates in each period an 'initial condition' for the future which is growth enhancing. (DAGDEVIREN et all $(2002$, p. 8).

Também em Ortiz surge alusão semelhante, no sentido de que "Poverty and inequality inhibit growth, depress domestic demand and hinder national economics development. developing countries with high inequality tend to grow slower" (2008, p. 7).

Na mesma direção é a conclusão do Banco Mundial no ano de 2006, representada no World Development Report, segundo o qual "sociedades desiguais são marcadas por grupos que têm, consistentemente, menos oportunidade - políticas, econômicas e sociais", restando evidente em mais esse documento, a relação estreita entre a igualdade, desigualdade de rendas 
e desenvolvimento. Ainda com base nesse relatório foi possível identificar que "reduções na desigualdade simultaneamente ao crescimento adicionam ao segundo um componente distributivo, e, por isso, podem reduzir a pobreza mais rapidamente" (COUTINHO 2013, p. $50)$.

Mas, não obstante as constatações empiricamente realizadas, Sen apresenta proposição pouco confortável aos cultores do desenvolvimento ao considerar possível que "tentativas de erradicar a desigualdade podem, em muitas circunstâncias, acarretar perda para a maioria - às vezes, até mesmo para todos" (2010, p. 127), fazendo concluir, com isso, que o desenvolvimento é um processo cuja complexidade deverá ser avaliada e sopesada, notadamente no que concerne aos seus custos e benefícios, a partir de cada realidade social. Exatamente desse fato se origina a difícil missão de promoção da equidade dentro de um ambiente de crescimento.

E ainda de acordo com Sen (2010, p. 120-121), mesmo que não se possa reduzir a desigualdade, revela-se imprescindível reconhecer que a pobreza e a riqueza podem estar relacionadas com as capacidades de cada ser humano (pobreza de capacidades), e sua relação com a renda, por consequência, associada a aspectos como a idade, papéis domésticos e sociais, localização e condições epidemiológicas.

Todavia, é diante dessa aparente contradição e contrariedade que se entende possível construir os pilares do desenvolvimento e as vias para a sua concretização.

Como visto, a desigualdade que impede o desenvolvimento tem muitas causas e agentes, conforme também registram Addison e Cornia (2001, p. 21), ao tratarem das políticas para o crescimento igualitário e a redução da pobreza. Ali, os autores sugerem que continuam as causas tradicionais do aumento da desigualdade ("reversing traditional causes of rising inequalitya”), indicando, entre outras, a destruição de terras pela via da reforma agrária.

Nessa tônica, e para fins propostos nesse estudo, as velhas causas também podem ser encontradas no mercado de trabalho, pelas constantes tensões entre seus agentes (empresários e empregados) na proteção dos seus interesses (lucro e salário, respectivamente); o acesso à educação e todas as repercussões que o mesmo assegura, seja com a melhoria da qualificação e os benefícios dessa ou com a marginalização imposta àqueles alijados do sistema, sem esquecer da globalização econômica e das assimetrias que o processo gera como resultado de uma política de desproteção ao nacional e concorrência internacional agressiva (COUTINHO, 2013,P. 55). 
Em suma e em uma avaliação abrangente, somente com a ampliação do ambiente distributivo, ter-se-ia a efetivação do desenvolvimento-direito, para o qual a igualdade é alicerce e estrutura imprescindível. Portanto, quer no campo da desigualdade natural, nascida com a evolução do gênero humano e do reconhecimento de virtudes e habilidades próprias de cada ser humano, quer na seara da desigualdade moral ou política, consistente nos diversos privilégios cujo usufruto é assegurado somente a alguns (ROUSSEAU, 2015, p. 102), reconhece-se que para a consecução de um desenvolvimento autossustentado pela mudança estrutural que promove, a baliza da igualdade é essencial.

Parece, pois, que devem ser feitos recortes sociais com vistas à promoção da igualdade enquanto instrumento do desenvolvimento. Identificado o ideal igualitário de cada específica realidade social, reduzidas as desigualdades e ampliados os acessos, estará efetivado o direito ao desenvolvimento.

O papel instrumental desse direito, portanto, é o de legitimar os sujeitos titulares a perseguirem a igualdade no acesso dos medidores de desenvolvimento humano a ser organizado de forma autossustetada ${ }^{6}$ garantindo o acesso por todos.

Em síntese, ainda que não seja condição suficiente, a igualdade é uma das estruturas de sustentação da obra de arte chamada desenvolvimento.

\subsection{Sobre a liberdade: percepções a partir de Amartya Sen}

Mas tratar do desenvolvimento e do direito ao desenvolvimento, implica inevitavelmente considerá-lo também como um processo de expansão das liberdades reais a serem desfrutadas por homens e mulheres (SEN, 2010, p. 16). Assim é que nesse novo contexto de desenvolvimento, medido a partir da equidade e indissociável da igualdade, a liberdade também tem ocupado seu espaço.

Em rasteira síntese, vinculada à ideia de ausência de intromissão estatal na esfera da vida do homem e em suas relações privadas, a liberdade sobre a qual comporta nessa passagem tratar é a que autoriza o exercício de direitos econômicos e sociais com vistas a aniquilar a formação de sociedades inigualitárias, erguidas mediante "a concessão de direitos apenas do ponto de vista formal" (RISTER, 2007, p. 130).

\footnotetext{
${ }^{6}$ Fábio Nusdeo (2013) faz uso da expressão desenvolvimento autossustentado para indicar o conceito econômico do termo sustentabilidade, deixando o adjetivo "sustentável" para o tratamento das questões ambientais. Na opinião das autoras, a sustentabilidade deve ser predicado de todas as dimensões do desenvolvimento, incluindose aí, não só a econômica, mas também a social, a política e a cultural.
} 
Para Sen o crescimento das rendas individuais é meio de expansão da própria liberdade a ser usufruída pela sociedade de modo a permitir que se removem as fontes de privação dessa mesma liberdade reconhecidas pela pobreza, tirania, carência de oportunidades econômicas, entre outras. As liberdades aparecem, pois, como "componentes constitutivos do desenvolvimento" (SEN, 2010, p. 19).

No entanto, pondera Rister que

[...] muito embora os rótulos da abordagem acima exposta possam estar associados à liberdade, o fato é que esta, pura e simples, não vinculada à busca da efetividade dos mencionados direitos econômicos e sociais, poderá levar a uma sociedade fortemente inigualitária, mediante a concessão de direitos apenas do ponto de vista formal, razão pela qual se faz necessário aprofundar a abordagem da liberdade, associando-a à busca da igualdade (2010, p. 130).

Discutindo o tema, Sen parece propor um diálogo de influências recíprocas que marcam o desenvolvimento e as liberdades. Nesse sentido, evidencia que "a privação da liberdade econômica pode gerar a privação de liberdade social, assim como a privação de liberdade social ou política pode, da mesma forma, gerar a privação de liberdade econômica" (2010, p. 23), do que decorreria o distanciamento do processo de desenvolvimento.

Reconhecido o valor das liberdades, Sen oferece classificação que tem como repercussão a compreensão das perspectivas de efetivação do desenvolvimento. Assim, as liberdade formais, ou liberties, indicam os chamados direitos individuais, ou seja, a liberdade que cada um tem de não ver tolhido o exercício de suas faculdades ou de seus direitos, exceto quando a lei determina”. São as liberdades sociais básicas asseguradas pelo judiciário e pelos órgãos da administração. Também integram a classificação de Sen as liberdades substantivas ou freedom, enquanto "liberdade de participação política ou a oportunidade de receber educação básica ou assistência médica”, ou seja, as que incluem capacidades elementares como ter condição de evitar privações, como fome, morte prematura e liberdades associadas como saber ler e fazer cálculos, ter participação política e liberdade (SEN, 2010, p. 55 e 82).

A liberdade também é destacada como essencial para o desenvolvimento do ser humano, devendo o seu exercício atender o interesse coletivo, "tutelado ou representado pelas expressões do poder" (GRAU, 1981, p. 3), para as quais comporta falar em limites de exercício do poder a fim de que não seja obstaculizado o exercício das liberdades. É, assim, a liberdade que respeita o outro.

Conforme pondera Anjos Filho, a realização da justiça está diretamente ligada à garantia de vida plena e "ao gozo de uma liberdade alargada" (2010, p. 135) enquanto requisitos para a efetivação da dignidade da pessoa humana. Como insiste o autor, não 
obstante esses elementos sejam reconhecidos na ordem do desenvolvimento humano, também o são no plano do desenvolvimento econômico, evidenciando a influência recíproca das formas de desenvolvimento.

Analisando os papéis da liberdade, Sen (2010, p. 33) aponta razões para se considerar a liberdade individual uma variável crucial no conceito de desenvolvimento e o faz relacionando com a avaliação e a eficácia. No campo avaliativo, o olhar se volta para as liberdades substantivas a serem usufruídas pelos cidadãos, colocando de fora de sua apreciação, elementos como utilidade, liberdade processual ou renda real. $\mathrm{Na}$ esfera da eficiência, a liberdade substantiva não é somente a base da avaliação de êxito e fracasso, mas diante dessa, são ampliados os potenciais de gestão endógenos e exógenos, fundamentais para o desenvolvimento.

Em suma, é pela liberdade que exsurge a possibilidade de perseguição, pela via do direito ao desenvolvimento, das variáveis do desenvolvimento humano (saúde, educação, cultura, trabalho, etc.) as quais, concedidas com respeito à igualdade, terão atingido o escopo de contribuírem para a efetivação do movimento autossustentado de desenvolvimento.

\section{CONSIDERAÇÕES FINAIS}

Diante das reflexões sobre a trajetória de construção do desenvolvimento e de formação do direito ao desenvolvimento, a partir dos pilares da igualdade e da liberdade, resta nessa seção conclusiva reunir os argumentos em torno da relação que entre essas se estabelece.

Comporta lembrar, para dar base às considerações finais, que o desenvolvimento é um processo que envolve a presença das dimensões econômicas, sociais, culturais e políticas que demandam, para a sua implementação, a estruturação de políticas públicas e planos de ação governamental. É notório que não há outra forma de fazê-lo.

Em verdade, como se viu, da gestão econômica nasce a possibilidade de implantação de políticas voltadas para a concretização do desenvolvimento humano, pelo que não se poderia admitir que fatores quantitativos fossem postos de lado ante o debate do desenvolvimento humano. Claro que os elementos políticos também compõem a ideia de desenvolvimento e representam o agir, tanto do povo como do indivíduo, na condição de sujeitos políticos, com vistas à realização da vida democrática.

No campo social, o desenvolvimento se revela na igualdade do ofertado pelo Estado e na atuação comprometida e cooperada entre esse e o conjunto dos cidadãos. A partir disso, 
ter-se-ia a proteção, pelo direito ao desenvolvimento, assegurando-se o direito ao trabalho, a educação em todos os níveis, a seguridade social, a moradia e a fruição de bens culturais, enfim, a todas as condições que se fazem indispensáveis ao bem-estar de cada um e de todos. Este é, em última análise, o que resulta da participação de cada um no processo de desenvolvimento e na fruição da produção em sentido lato. Tal não se faz sem a base de oportunidades, sempre assentadas na liberdade e na redução das desigualdades.

Desse modo, o que se tem como certo é a necessidade da estruturação de mecanismos jurídicos de garantia do desenvolvimento, a partir da consolidação das bases científicas do direito ao desenvolvimento, de modo que o individualismo que conduz a vida dos próprios titulares desse direito não acabe marcando o direito ao desenvolvimento com o símbolo do fracasso ou da pouca concreção.

$\mathrm{Na}$ certeza da dificuldade de discutir desenvolvimento no contexto de crise humanitária imperante no mundo, não menos confortável é a missão de, recortando o termo desenvolvimento, revisitar a igualdade e a liberdade, para, a partir destas legitimar o exercício do direito ao desenvolvimento.

Ainda assim, importante reconhecer o valor dos debates que têm se firmado em todo o mundo com o escopo de refletir sobre o desenvolvimento e o direito ao desenvolvimento, assim, no campo das relações internacionais, do direito do trabalho, com as convenções da OIT, do consumo, saúde e meio ambiente, no exercício da justiça e da democracia.

Diante disso comporta concluir que a efetivação do novo desenvolvimento, humano e fundamental, intra e intergeracional, nacional e internacional e autossustentado, tendo em sua base a interação entre os agentes econômicos, encontra na instrumentalidade do direito ao desenvolvimento uma via valiosa de efetivação.

O desenvolvimento, com todos os seus papéis de categoria multidimensional, exige que a sociedade se aproxime dos instrumentos viabilizadores desse mesmo desenvolvimento para que, juntamente com o Estado, seja efetivado o crescimento equitativo, motor da inclusão social e experiência de justiça social.

Assim, há sempre a expectativa de que sejam superadas as barreiras para o avanço na efetivação desse direito, com a investigação sobre os caminhos de igualdade e liberdade a serem identificados em cada realidade social.

\section{REFERÊNCIAS}

ADDISON, Tony; CORNUA, Gionvanni Andrea. Income Distribuition Policies for faster poverty reducition. UNU World Institute for Development Economics Research (UNU 
WUNDER). Disponível em: https://www.wider.unu.edu/publication/income-distributionpolicies-faster-poverty-reduction. Acesso em 26 mar. 2018.

ANJOS FILHO, Robério Nunes. Fontes do direito ao desenvolvimento no plano internacional. In: Flávia Piovesan et al (Coords). Direito ao desenvolvimento. Belo Horizonte: Fórum, 2010.

World Bank. World Development Report: Iguality and Development. Banco Mundial: Washington, 2006. Disponível em: https://openknowledge.worldbank.org/bitstream/handle/ 10986/5988/WDR\%202006\%20-\%20English.pdf?sequence=3\&isAllowed=y. Acesso: 22 mar. 2018.

CALLEGARI, José Carlos. Desenvolvimento econômico, direito do trabalho e direitos sociais - uma análise das Convenções da Organização Internacional do Trabalho. In.: Flávia Piovesan et al (Coords.). Direito ao desenvolvimento. Belo Horizonte: Fórum, 2010, p. 491513.

CAMPINHO, Bernardo Brasil. O direito ao desenvolvimento como afirmação dos direitos humanos: delimitações, sindicabilidade e possibilidades emancipatórias. In.: Direito ao desenvolvimento. Flávia Piovesan et al (Coords.). Belo Horizonte: Fórum, 2010, p 153-178. CECATO, Maria Aurea Baroni Cecato. Direitos laborais e desenvolvimento: Interconexões. Boletim de Ciências Económicas de Coimbra. Universidade de Coimbra, v. LI, 2008, p. 173-191.

COUTINHO, Diogo R. Direito, desigualdade e desenvolvimento. São Paulo: Saraiva, 2013. DAGDEVIREN, H.; VAN DER HOEEN, R.; WEEKS, J. Redistribution Does Matter. UNU World Institute for Development Economics Research (UNU-WIDER). WIDER, Discussion Paper n. 2002/5. Disponível em https://www.wider.unu.edu/sites/default/files/ dp2002-05.pdf. Acesso em 14 mar. 2018.

DELGADO, Ana Paula Teixeira. O Direito ao Desenvolvimento na perspectiva da Globalização: Paradoxos e Desafios. São Paulo: Renovar, 2001.

FACHIN, Melina Girardi. Direito fundamental ao desenvolvimento - Uma possível ressignificação entre a Constituição Brasileira e o Sistema Internacional de Proteção dos direitos humanos. In.: Direito ao desenvolvimento. Coord. Flávia Piovesan et al. Belo Horizonte: Fórum, 2010.

FEITOSA, Maria Luiza P. Alencar Mayer. In: Direito Econômico da Energia e do Desenvolvimento: Ensaios interdisciplinares. São Paulo: Conceito, 2012. Direito 
Econômico da Energia e Direito Econômico do Desenvolvimento. Superando a visão tradicional.

Direito econômico do desenvolvimento e direito humano ao desenvolvimento.

Limites e Confrontações. In: Direitos humanos de solidariedade: Avanços e Impasses.

Curitiba: Apris, 2013, p. 171-269.

FURTADO, Celso. Em busca do novo modelo. Rio de Janeiro: Paz e Terra, 2002.

GRAU, Eros. A ordem econômica na Constituição de 1988. São Paulo: Malheiros, 2010.

Elementos de Direito Econômico. São Paulo: Ed. Revista dos Tribunais, 1981.

GREEN, Duncan. Da pobreza ao poder. São Paulo: Cortez; Oxford; Oxfam Internacional, 2009.

NUSDEO, Fábio. Curso de Economia: Introdução do Direito Econômico. 10a ed. São

Paulo: Ed. Revista dos Tribunais, 2016.

ORTIZ, Isabel. Social Policy. National Development Strategies - Policy notes. United

Nations, Departament of Economic and Social Affair. New York. Disponível em:

file://C:/Users/PCA/Desktop/PN_SocialPolicyNote.pdf. Acesso em 26 mar. 2018.

ORGANIZAÇÃO DA UNIDADE AFRICANA (OUA): Carta Africana dos Direitos do

Homem e dos Povos. Disponível em: http://www.achpr.org/pt/instruments/achpr/. Acesso em 05 mai. 2017.

ORGANIZAÇÃO DAS NAÇÕES UNIDAS: Declaração sobre o direito ao

desenvolvimento. Nova York, 1986. Disponível em http://direitoshumanos.gddc.pt/3_16/

IIIPAG3_16_5.htm. Último acesso em 02.04.2017.

PEREZ LUÑO, Antonio Enrique de. Dimensiones de la igualdad. Madrid: Dykinson., 2005. PERROUX, François. Ensaio sobre a filosofia do novo desenvolvimento. Lisboa: Fundação Calouste Gulbenkain, 1981.

PIOVESAN, Flávia. Direito ao Desenvolvimento: Desafios contemporâneos. In. Flávia

Piovesan et al (Coords.). Direito ao desenvolvimento. Belo Horizonte: Fórum, 2010, p. 95 116.

Direito ao Desenvolvimento: Antecedentes, significados e consequências. Rio de Janeiro: Renovar, 2007.

ROUSSEAU, Jean-Jacques. Discurso sobre a origem e os fundamentos da desigualdade entre os homens. São Paulo: Edipro, 2015.

SANTOS, Adrianna de Alencar Setubal. O direito ao desenvolvimento e a livre iniciativa: confluência a partir da liberdade. Florianópolis: CONPEDI São Luis, 2017. Disponível em 
https://www.conpedi.org.br/publicacoes/27ixgmd9/ y800859o/r1Mz255j5RRzg3Rd.pdf.

Acesso em 26 mar. 2018.

SACHS, Jefrey. O fim da pobreza: como acabar com a miséria mundial nos próximos vinte anos. São Paulo: Companhia de letras, 2005.

SEN, Amartya. Sobre ética e economia. São Paulo: Companhia das Letras, 1999. Desigualdade reexamida. São Paulo: Record, 2001. Desenvolvimento como liberdade. São Paulo: Companhia de Bolso, 2010. A ideia de justiça. São Paulo: Companhia das Letras, 2011.

SOARES, Inês Virgínia Prado. Direito ao desenvolvimento e justiça de transição: conexões e alguns dilemas. In: Flávia Piovesan et al (Coords.). Direito ao desenvolvimento. Belo Horizonte: Fórum, 2010.

TRUBEK, David M. O "império do direito" na ajuda ao desenvolvimento: passado, presente e futuro. In.: RODRIGUEZ, José Rodrigo et al (Orgs.). O novo direito e desenvolvimento: presente, passado e futuro - textos selecionados de David M. Trubek. São Paulo: Saraiva, 2009. 